Arch. Dis. Childh., 1964, 39, 397.

\title{
HYPERGLYCINAEMIA AND HYPERGLYCINURIA IN A NEWBORN INFANT
}

\author{
BY \\ H. K. A. VISSER, H. W. VEENSTRA, and C. PIK \\ From the Department of Paediatrics, State University, Groningen, The Netherlands
}

(RECEIVED FOR PUBLICATION NOVEMBer 21, 1963)

Hyperglycinaemia and hyperglycinuria is a relatively new disorder of amino acid metabolism. The first patient with this disease was described by Childs, Nyhan, Borden, Bard, and Cooke in 1961; since then two other cases have been reported (Nyhan, Chisolm, and Edwards, 1963; Cochrane, Scriver, and Krause, 1963). The histories of these cases demonstrate that severe manifestations of the disorder may develop in the immediate neonatal period, the most striking features being vomiting, irregular breathing, weak reflexes, and flaccidity, together with metabolic acidosis and ketonuria. The precise underlying defect, probably in the metabolism of glycine, has not so far been elucidated. Family histories give some evidence that this disease is a genetic disorder. In two of the three families reported, other sibs died, probably with the same disease, in early infancy. In the third family two earlier pregnancies ended in miscarriages.

We report here another infant with hyperglycinaemia and hyperglycinuria, a boy, who died at 4 days with flaccidity and irreversible respiratory acidosis. The family history of this patient is remarkable: three earlier pregnancies ended in miscarriages; two sibs (both boys) died in the first days of life with the same clinical syndrome. One normal girl is alive. This familial incidence gives strong support for the hereditary character of this disorder.

\section{Case Report}

Baby G. was admitted to a local hospital, at 1 day, after a normal pregnancy and delivery. Birth weight was $3,530 \mathrm{~g}$. Because of the family history and the weak reflexes of the baby, he was sent to the Department of Paediatrics, State University Hospital, Groningen. This 36-hour-old male baby demonstrated marked muscular hypotonia; there was a weak Moro reflex, a poor sucking reflex, and the grasp reflex was absent. Otherwise the physical examination was normal.

The mother was 31 and the father 32 years old. Pregnancies in 1954 and in 1959 ended in miscarriages after three months. In 1957 and 1960 after normal pregnancies and deliveries two sibs, both male, died at the age of 3 days with the same clinical syndrome: irregular br zathing and extreme flaccidity. These symptoms started about 12 hours after birth. Necropsy of the baby in 1960 was unremarkable. In 1961 a pregnancy ended after five months, the newborn male baby died immediately. The pedigrees of the father and the mother could be traced back for five generations. There is no consanguinity in the very large families. The father has two sisters; the mother has four brothers. Two brothers of the maternal grandmother died at a young age, reason unknown. The maternal grandmother had four sisters who all had more than six children each and many grandchildren of both sexes. No specific indications are given in these pedigrees.

Laboratory examination revealed leucocytes 8,400 , polymorphonuclear cells $65 \%$, lymphocytes $35 \%$. Haematocrit $68 \%$, haemoglobin concentration 18.5 g.l $100 \mathrm{ml}$. Blood chemistry at admission: $\mathrm{Na} 138, \mathrm{~K} 4 \cdot 2$, Cl $101 \mathrm{mEq} / 1$. ; urea $16.6 \mathrm{mg}$./100 ml., Ca 9.5, P 6.6 mg./ $100 \mathrm{ml}$. Metabolic acidosis was indicated by $p \mathrm{H} 7 \cdot 19$, standard bicarbonate $12 \cdot 1 \mathrm{mEq} / \mathrm{l}, \mathrm{PcO}_{2} 32 \mathrm{~mm} . \mathrm{Hg}$ (Astrup, Jørgensen, Andersen, and Engel, 1960).

Fluid was given by intravenous drip in the umbilical vein at a rate of $6 \mathrm{ml}$. per hour. The electrocardiogram at this time demonstrated remarkable abnormalities (Fig. 1, 40 hours) compared with the relatively normal features eight hours earlier in the local hospital (Fig. 1, 32 hours). The main ECG changes were prolonged and depressed $T$ waves, as is seen in hypokalaemia. $T$ time (after correction) was $0.40 \mathrm{sec}$., P-R interval $0.12 \mathrm{sec}$. Electrocardiograms later showed more depressed, even flat T waves (Fig. 1, 43 and 56 hours).

During the next 48 hours the condition of the child became increasingly worse. There was irregular breathing, pre-terminally of Cheyne-Stokes type, with periods of apnoea and cyanosis. The thoracic excursions were very small. There was extreme flaccidity and ultimately no reaction at all to several stimuli. Convulsions occurred on the second day. The biochemical data, particularly $p \mathrm{H}$, standard bicarbonate, and $\mathrm{Pco}_{2}$ are given in Table 1 . Treatment was glucose $5 \%$, invert sugar $10 \%$, and sodium bicarbonate $4 \cdot 2 \%$ intravenously, while at 84 hours $24 \mathrm{ml}$. of trishydroxy-methyl-aminomethane (THAM) 3.67 buffer were given. The baby died at 97 hours in irreversible 


\begin{tabular}{|c|c|c|c|c|c|c|c|c|c|c|}
\hline \multirow{2}{*}{$\begin{array}{l}\text { Age } \\
\text { (hr.) }\end{array}$} & \multicolumn{10}{|c|}{ Blood } \\
\hline & $\underset{(m E q / 1 .)}{N a}$ & $\underset{(\mathrm{mEq} / \mathrm{l} .)}{\mathrm{K}}$ & $\underset{(m E q / 1)}{C l}$ & $\begin{array}{c}\text { Urea } \\
\text { (mg./100 ml.) }\end{array}$ & $\begin{array}{c}\mathrm{Ca} \\
(\mathrm{mg} . / 100 \mathrm{ml} .)\end{array}$ & $\stackrel{P}{\mathbf{P}}$ & $p \mathbf{H}$ & $\begin{array}{c}\text { St. Bicarb. } \\
\text { (mEq/l.) }\end{array}$ & $\underset{(\mathrm{mm} . \mathbf{H g})}{\mathrm{PCO}_{2}}$ & $\underset{\text { (mg-/100 ml.) }}{\text { Bilirubin }}$ \\
\hline $\begin{array}{l}36 \\
43\end{array}$ & 138 & $\begin{array}{l}4 \cdot 2 \\
4 \cdot 1\end{array}$ & 101 & $16 \cdot 6$ & $9 \cdot 5$ & $6 \cdot 6$ & $\begin{array}{l}7 \cdot 19 \\
7 \cdot 32\end{array}$ & $\begin{array}{l}12 \cdot 1 \\
21 \cdot 5\end{array}$ & $\begin{array}{l}32 \\
47 \cdot 5\end{array}$ & $6 \cdot 8$ \\
\hline $\begin{array}{l}55 \\
64\end{array}$ & & $4 \cdot 1$ & & & $8 \cdot 8$ & $6 \cdot 8$ & $\begin{array}{l}7 \cdot 23 \\
6 \cdot 99\end{array}$ & $\begin{array}{l}19 \cdot 5 \\
13 \cdot 2\end{array}$ & $\begin{array}{r}61 \\
105\end{array}$ & $9 \cdot 1$ \\
\hline $\begin{array}{l}69 \\
79 \\
84\end{array}$ & 139 & $4 \cdot 4$ & & & & & $\begin{array}{l}7 \cdot 09 \\
7 \cdot 00 \\
6 \cdot 89\end{array}$ & $\begin{array}{l}18 \cdot 5 \\
19 \cdot 5 \\
16\end{array}$ & $\begin{array}{r}93 \\
144 \\
>150\end{array}$ & \\
\hline 90 & & & & & & & $6 \cdot 83$ & $19 \cdot 2$ & $>150$ & \\
\hline
\end{tabular}

Note that the metabolic acidosis could be adequately treated witn sodium bicarbonate. Ultimately an irreversible respiratory acidosis developed.

respiratory acidosis. About $\mathbf{4 0} \mathrm{ml}$. urine was voided and partially collected. Chemistry was $\mathrm{Na} 33, \mathrm{~K} 54 \cdot 5, \mathrm{Cl}$ $35.5 \mathrm{mEq} / 1$., P 216.5, Ca $14 \mathrm{mg} . / 100 \mathrm{ml}$. Reaction on acetone was slightly positive.

The necropsy (performed by Dr. E. H. Ebels, Department of Pathology, State University) revealed no specific abnormalities. There was a fatty degeneration of the liver; in one of the lungs a small abscess was found.

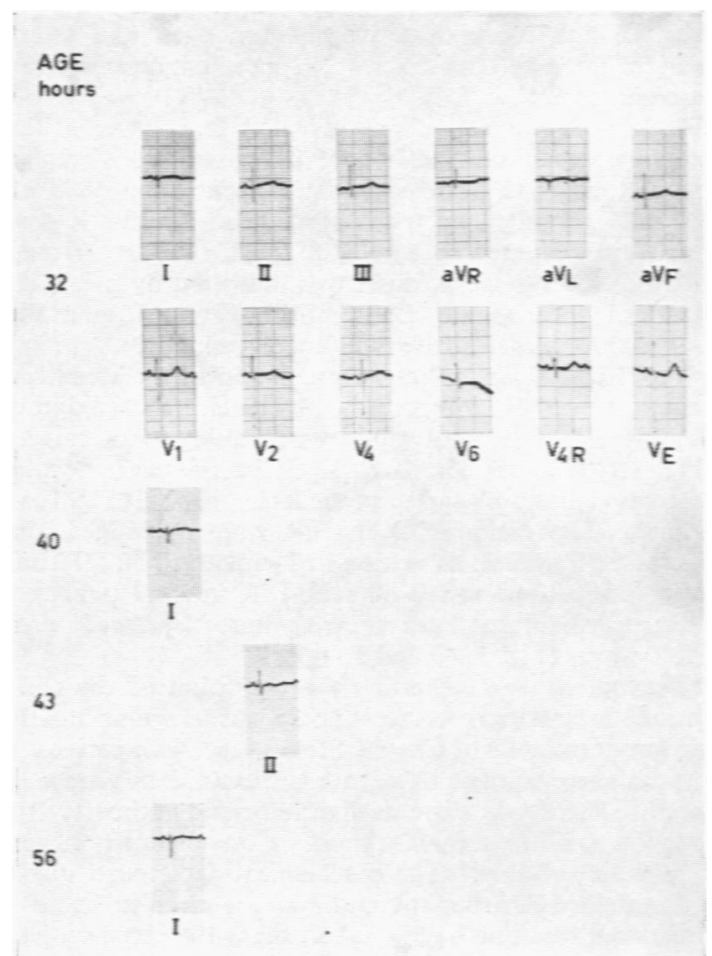

FIG. 1.-Changes in the electrocardiogram of the patient. Note the rapidly increasing abnormalities of repolarization: the $T$ waves are depressed.
Microscopically no abnormalities were seen. There was no increase in iron-containing pigment in the Kupffer and parenchymal cells in the liver, nor in the reticuloendothelial cells of the spleen and marrow.

\section{Special Laboratory Investigations}

Urinary keto acids were semi-quantitatively estimated by adding 2-4-dinitrophenylhydrazine in $2 \mathrm{~N}$ hydrochloric acid. The precipitate was extracted with ether, and subsequently the ether was extracted with sodium carbonate. The yellow colour was compared with that of control urines by measuring the extinction at $520 \mathrm{~m} \mu$. The keto acids in the patient's urine were shown to be increased threefold.

The keto acids were identified using the method described by Towers, Thompson and Steward (1954). The 2-4-dinitrophenylhydrazine derivatives of the keto acids were reduced; by paper chromatography, mainly alanine was identifisd.

Neutral and acidic amino acids in plasma and urine of the baby and his parents were estimated by the photoelectric ninhydrin method of Moore and Stein (1954) using an automatic Spinco-Beckman analyser. Plasma was deproteinated with picric acid (Stein and Moore, 1954). Determination of basic amino acids was not done.

Urinary amino acids were also estimated semi-quantitatively using high-voltage electrophoresis (the procedure is described by Puranen, Puranen and Hallman, 1958), scanning the paperstrips with a Spinco analytical scanning apparatus.

\section{Results}

High voltage electrophoresis of the patient's urine revealed a high excretion of glycine (Fig. 2 and Table 2) while other amino acids were excreted in normal or slightly increased amounts, compared with control data. Urinary excretion of amino acids in the parents of the patient was within the normal range.

Excretion of alanine in the patient's urine was little below that of controls, as was also the case in the first two patients with hyperglycinaemia (Childs et al., 1961 ; Nyhan et al., 1963). 


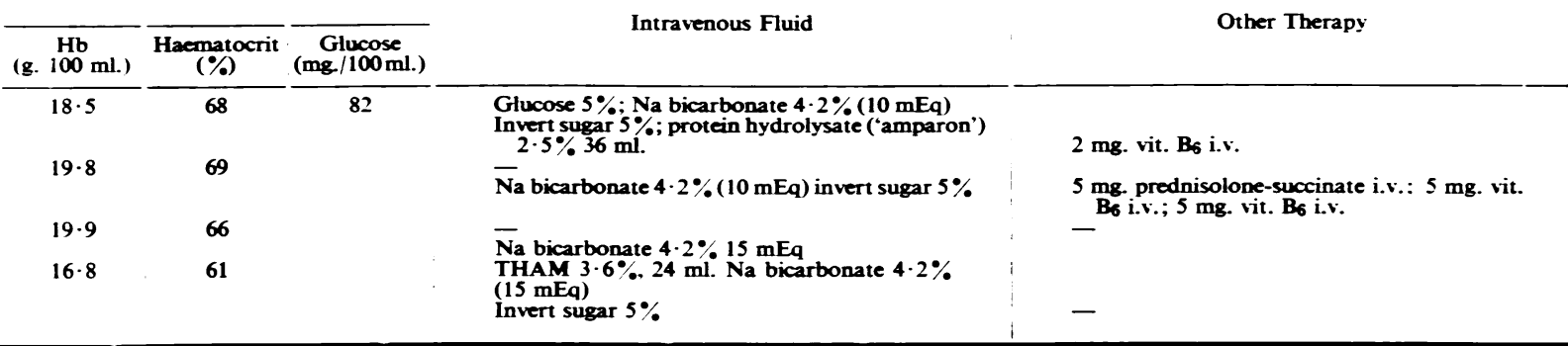

TABLE 2

URINARY AMINO ACID EXCRETION ( $\mu \mathrm{M} / \mathrm{kg} / 24 \mathrm{hr}$.)

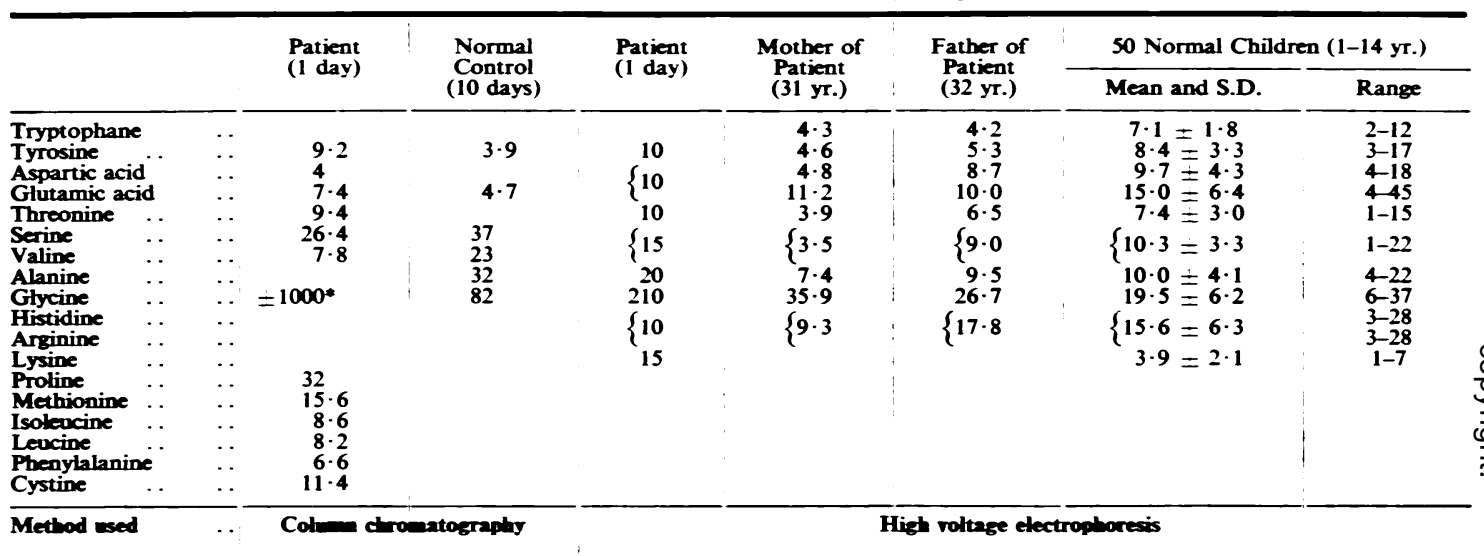

Values not mentioned in this table were too low or for other reasons were not calculated. - Calculated after separate run of diluted urine.

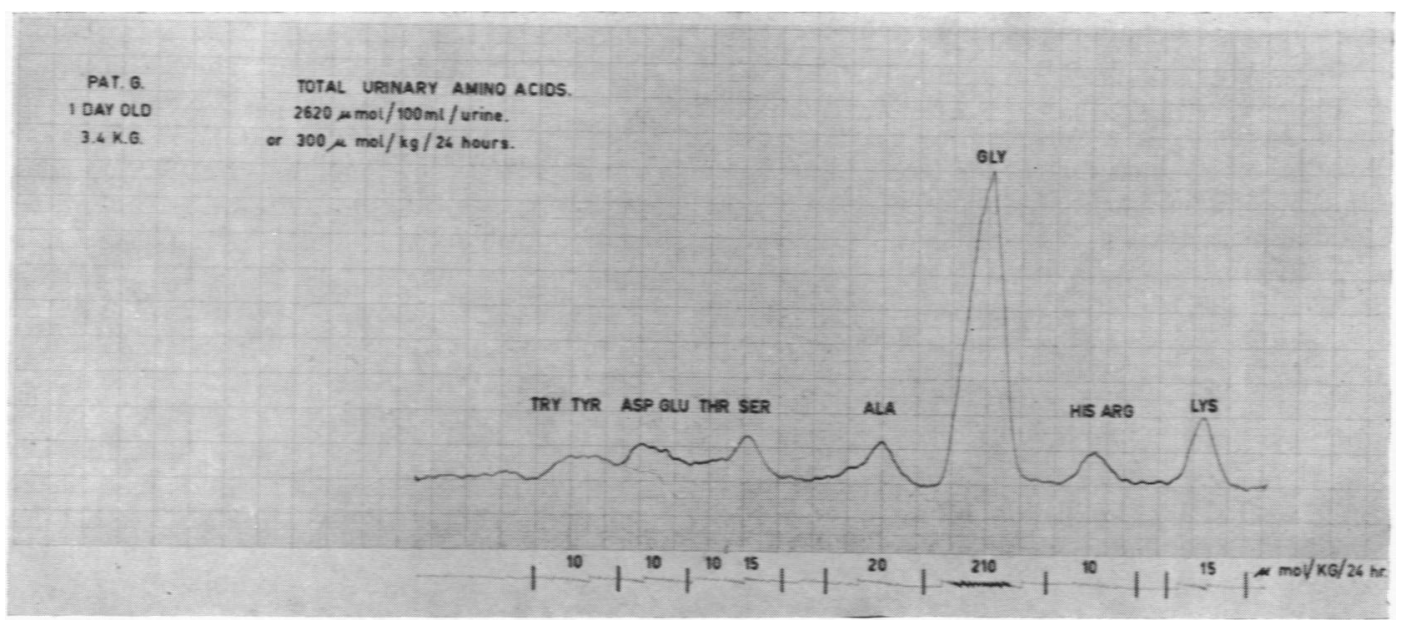

FKG. 2.-Semiquantitative determination of the urinary amino acids in the patient (high-voltage electrophoresis); try = tryptophane: tyr = tyrosine; asp = aspartic acid; glu = glutamic acid; thr = threonine; ser $=$ serine: ala $=$ alanine: gly = glycine; his = histidine: arg $=$ arginine; lys $=$ lysine. 
TABle 3

FREE AMINO ACIDS IN PLASMA (: $2 \mathrm{M} 100 \mathrm{ml}$.

\begin{tabular}{|c|c|c|c|c|c|c|c|c|}
\hline & & & \multirow{2}{*}{$\begin{array}{l}\text { Patient } \\
\text { (1 day) }\end{array}$} & \multirow{2}{*}{$\begin{array}{l}\text { Normal } \\
\text { Control } \\
\text { (10 days) }\end{array}$} & \multirow{2}{*}{$\begin{array}{l}\text { Father of } \\
\text { Patient } \\
\text { (32 yr.) }\end{array}$} & \multirow{2}{*}{$\begin{array}{l}\text { Mother of } \\
\text { Patient } \\
\text { (31 yr.) }\end{array}$} & \multicolumn{2}{|c|}{ Normal Adult Controls } \\
\hline & & & & & & & $\begin{array}{c}\text { Male } \\
\text { (34 yr.) }\end{array}$ & $\begin{array}{l}\text { Female } \\
(30 \mathrm{yr} .)\end{array}$ \\
\hline 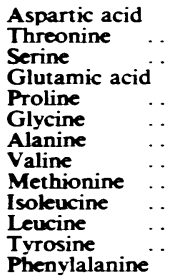 & $\begin{array}{l}\cdots \\
\cdots \\
\cdots \\
\cdots \\
\cdots \\
\cdots \\
\cdots \\
\cdots \\
\cdots \\
\cdots\end{array}$ & $\begin{array}{l}\ldots \\
\cdots \\
\cdots \\
\cdots \\
\cdots \\
\cdots \\
\cdots \\
\cdots \\
\cdots \\
\cdots\end{array}$ & $\begin{array}{l}3 \cdot 5 \\
54 \cdot 5 \\
372 \\
81 \cdot 5 \\
150 \\
930 \\
281 \\
86 \cdot 5 \\
18 \cdot 5 \\
75 \cdot 5 \\
88 \cdot 5 \\
24 \\
37\end{array}$ & $\begin{array}{l}2 \\
19 \\
120 \\
17 \cdot 5 \\
62 \\
39 \\
70 \\
42 \\
3 \\
19 \cdot 5 \\
19 \cdot 5 \\
34 \\
10\end{array}$ & $\begin{array}{l}2 \\
26 \\
112 \\
12 \\
114 \\
65 \\
66 \cdot 5 \\
56 \cdot 5 \\
5 \cdot 5 \\
32 \cdot 5 \\
26 \cdot 5 \\
16 \\
10 \cdot 5\end{array}$ & $\begin{array}{c}2 \\
35 \cdot 5 \\
101 \\
7 \cdot 5 \\
75 \\
62 \cdot 5 \\
102 \cdot 5 \\
58 \\
3 \cdot 5 \\
30 \cdot 5 \\
29 \\
18 \cdot 5 \\
10 \cdot 5\end{array}$ & $\begin{array}{r}76 \\
98 \\
9 \\
75 \\
92 \\
36 \\
44 \\
4 \\
28 \\
25 \\
8 \\
14\end{array}$ & $\begin{array}{r}35 \\
97 \\
8 \\
65 \\
77 \\
41 \\
30 \\
4 \\
15 \\
15 \\
9 \\
16\end{array}$ \\
\hline
\end{tabular}

In Table 2 data for urinary amino acid excretion in the patient, a normal control baby, the parents of the patient, and 50 normal children (1-14 years old) are given. Data for the patient and the control baby are given using both column chromatography and high-voltage electrophoresis.

Free amino acids in plasma were estimated by column chromatography and the results are presented in Table 3 . In the patient almost all amino acids were found in higher concentrations compared with control data. The study of amino acids by column chromatography is laborious and time consuming, and we have not enough control data available for statistical analysis. However, for general comparison the data reported in Table 3 can be used, and an increase of two to five times in the patient's plasma of all amino acids except glycine was recorded, and can be compared with the normal control baby and the data for two normal adults. It is interesting to note that for these amino acids the increased plasma levels are not reflected in increased excretion in the urine, except for glycine which was present in a considerably higher concentration, i.e. 10-20 times that of the control data.

Amino acid concentrations in the plasma of the parents demonstrate no significant differences compared with two normal adult controls, except perhaps for the slightly raised concentrations of alanine in the mother and proline in the father.

\section{Discussion}

The hyperglycinaemia and hyperglycinuria together with some clincial symptoms classify this patient with reasonable certainty as the fourth patient with hyperglycinaemia, a relatively new disorder of amino acid metabolism.

The first patient with this syndrome was reported by Childs et al. (1961). This 3-year-old boy was studied extensively by these workers, and some data on this patient are also reported by Di George and Auerbach (1963). His illness began 18 hours after birth with vomiting, hyperpnoea, acidosis, and ketonuria. During the next months and years periodic vomiting with ketosis, often associated with respiratory infections, was observed. Other features of the disease as summarized by Childs and coworkers were: neutropenia, periodic thrombocytopenia, hypo- $\gamma$-globulinaemia, osteoporosis, and developmental retardation. Their patient demonstrated an intolerance of protein when given in an amount of more than $0.5 \mathrm{~g} . \mathrm{kg}$. day, of protein hydrolysate, and of the amino acid leucine. Restriction of the dietary intake of protein resulted in a decrease in the concentrations of glycine and several other amino acids in the blood and urine, while the frequency and severity of episodes of acute illness decreased. This patient was the third child in the family; two earlier pregnancies ended in miscarriages.

The second patient, interpreted by the investigators as having hyperglycinaemia, is reported by Nyhan et al. (1963). His illness started at 4 months of age when he developed severe dehydration and acidosis with a minor respiratory infection. The urine was strongly positive for acetone. A male sib had died at $\mathbf{4}$ days with symptoms suggesting the same disease, i.e. irregular breathing, cyanosis, flaccidity. This boy appeared well at birth but failed to nurse on the second day. This second patient, as studied by Nyhan and co-workers, later demonstrated some characteristic clinical features, e.g. recurrent episodes of metabolic acidosis and ketonuria with vomiting and lethargy, these episodes being often associated with acute infections. There was developmental retardation, osteoporosis, thrombocytopenia, and neutropenia. Only urine was available for aminoacid analysis: glycinuria was present with concentrations 10 times those of control patients. There was 
a relation between leucocyte counts and glycinuria during a short period with essentially no protein intake. This patient died at 16 months of age during a period with an increasing number of episodes of vomiting, anorexia, and acidosis. Necropsy revealed nothing significant.

The third patient with hyperglycinaemia and hyperglycinuria is described by Cochrane et al. (1963). A 12-day-old infant was seen on account of vomiting, listlessness, dehydration, and metabolic acidosis with ketonuria. Amino acids were analysed in plasma and urine. A generalized aminoaciduria was found with a large amount of glycine. Plasma concentrations of glycine and several other amino acids were raised. Full details of these studies are not available as yet, as this work is published as an abstract. Neutropenia and thrombocytopenia are mentioned. The infant died at $\mathbf{2}$ months of age in coma with irreversible acidosis. Necropsy revealed an increase in iron-containing pigment in the Kupffer and parenchymal cells in the liver, and also in the macrophages and reticuloendothelial cells of spleen and marrow. In this family a previous sib had died at 2 weeks, probably with the same disease.

The precise underlying defect in amino acid metabolism for this disorder is not known. Childs and co-workers studied their patient extensively but failed to find a metabolic defect in one of the pathways of glycine metabolism (Childs et al., 1961; Nyhan, Borden, and Childs, 1961). Some evidence has been found for an abnormality in the conversion of glycine to serine; using isotopically-labelled glycine, Nyhan and Childs (1962) found a considerably greater pool size of glycine in the child with hyperglycinaemia compared with control subjects. Although Childs et al. (1961) considered an impaired heme formation from glycine via delta-aminolaevulinic acid unlikely because their patient always had normal haemoglobin values, Cochrane et al. (1963) suggested, as the basic defect, a failure in incorporation of glycine in the porphyrin pathway, resulting in excess iron deposits in the liver and reticuloendothelial system. Di George and Auerbach (1963) tentatively placed the metabolic defect at glycine oxidase which converts glycine to glyoxylic acid, but as yet there is no proof for this assumption.

Di George and Auerbach (1963) have pointed out that the rarity of recognition of the disorder may be explained by the severe manifestations in the first days of life, which may lead to early death. Other cases may already die in utero. An important symptom of this disease in the neonatal period may be the presence of acetone. Ketonuria is very unusual during the first days of life (Heymann, 1938) and the urines of sick babies should be routinely examined for acetone. The diagnosis of hyperglycinuria may give some difficulties when paper chromatographic methods are employed: the glycine spot is already quite pronounced in normal urines. Using high-voltage electrophoresis, an increased excretion of glycine may well be diagnosed more easily and, of course, when doubt arises plasma analysis should be performed.

The differential diagnosis of hyperglycinaemia and hyperglycinuria presents in a few diseases and is not difficult. Glycinuria as described by de Vries, Kochwa, Lazebnik, Frank, and Djaldetti (1957) is probably a genetic renal tubular defect without increased concentrations of glycine in plasma. Clinically these patients have nephrolithiasis and do not show the characteristic features of hyperglycinaemia. Glucoglycinuria was described by Käser, Cottier, and Antener (1962) as a familial syndrome and glucosuria is an essential symptom, together with increased urinary excretion of glycine. The familial disorder described by Schafer, Scriver, and Efron (1962) as familial hyperprolinaemia with hereditary deafness and nephropathy is a renal tubular defect with glycinuria and prolinuria.

Maple syrup urine disease (Menkes, 1959) may give a clinical syndrome in the newborn baby that is difficult to differentiate without more extensive laboratory investigations. The case described by Woody, Woody, and Tilden (1963) presents the same clinical symptoms as are reported in the infants with hyperglycinaemia. Older children with maple syrup urine disease are mentally retarded but do not show other characteristic features of hyperglycinaemia. Urine, particularly in the sick newborn baby, should be investigated for the presence of the $\alpha$-keto acids derived from the branched chain amino acids leucine, isoleucine, and valine (Dancis, Levitz, and Westall, 1960).

Reporting our patient we present few facts that have not been mentioned already by the authors of the three papers dealing with this disease. But as Nyhan et al. (1963) have stated the report of additional examples of the disease appears desirable, for recognition of more than one patient has implications for more widespread diagnosis as well as for the development of effective methods of therapy'. Our patient is the first to be reported in the European literature, and we hope that this paper will suggest early diagnosis of other patients.

The family history of our patient provides strong evidence that hyperglycinaemia is an inherited metabolic disease. Clinically the most striking symptom was the extreme flaccidity and muscular hypotonia; the metabolic acidosis could be treated 
adequately, but the child died in irreversible respiratory acidosis. The rapidly increasing deterioration of the electrocardiogram can be interpreted as reflecting the intracellular metabolic disturbances.

The severe manifestations of the disease in this family leading to early death in the neonatal period demonstrate, when compared with the histories of the other reported patients, that different degrees of severity of the syndrome exist, as in other inborn errors of metabolism.

\section{Summary}

A case of hyperglycinaemia and hyperglycinuria is reported, a newborn male infant who died 4 days after birth with extreme flaccidity and severe respiratory acidosis.

Amino acid analysis in the patient's urine revealed a much increased glycine excretion. Plasma concentrations of most amino acids were increased to 2-3 times those of control values, with the exception of glycine which was 10-20 times the control value.

Amino acid analysis of plasma and urine of the parents of the patient showed normal values.

Three other cases of hyperglycinaemia are shortly reviewed. The family history of our patient gives support to the hereditary character of this disease.

We are grateful to Dr. J. H. Janssen, paediatrician, who referred the patient to us and gave his clinical notes; to Dr. E. H. Ebels, Dept. of Pathology, State University, Groningen, for his help; to Dr. K. K. Bossina, Dept. of Paediatrics, State University, Groningen, for his advice on the electrocardiograms. Dr. Angelo Di George, Christopher's Hospital for Children, Philadelphia, Pa. U.S.A., was very kind in making information about patients available. Two mentally retarded sibs, 3 and 8 years old, with hyperglycinaemia and hyperglycinuria have been reported recently by Dr. C. Charlton Mabry and
Dr. Edmund A. Karam (University of Kentucky School of Medicine, Lexington, Kentucky, U.S.A.) at a meeting of the Southern Society for Paediatric Research (U.S.A.).

\section{REFERENCES}

Astrup, P., Jergensen, K., Andersen, O. S. and Engel, K. (1960). The acid-base metabolism. A new approach. Lancet, 1. 1035.

Childs, B., Nyhan, W. L., Borden, M., Bard, L. and Cooke. R. E (1961). Idiopathic hyperglycinemia and hyperglycinuria: A new disorder of amino acid metabolism. I. Pediatrics, 27, 522.

Cochrane, W., Scriver, C. R. and Krause, V. (1963). Hyperglycinemia-hyperglycinuria syndrome in a newborn infant. Abstracts Soc. Pediat. Research, Atlantic City, May 1, p. 102.

Dancis, J., Levitz, M. and Westall, R. G. (1960). Maple syrup urine disease: brancher-chain keto-aciduria. Pediatrics, 25, 72

de Vries, A., Kochwa, S., Lazebnik, J., Frank, M. and Djaldetti, M. (1957). Glycinuria, a hereditary disorder associated with nephrolithiasis. Amer. J. Med., 23, 408.

Di George, A. M and Auerbach, V. H. (1963). The primary aminoacidopathies. Pediat. Clin. N. Amer., 10, 723.

Heymann. W. (1938). Metabolism studies on age disposition to ketosis in human beings. J. Pediat., 12, 21.

Kāser, H., Cottier, P. and Antener, I. (1962). Glucoglycinuria, a new familial syndrome. ibid., $61,386$.

Menkes, J. H. (1959). Maple syrup disease. Isolation and identification of organic acids in the urine. Pediatrics, 23, 348.

Moore, S. and Stein, W. H. (1954). A modified ninhydrin reagent for the photometric determination of amino acids and related compounds. J. biol. Chem., 211, 907.

Nyhan. W. L., Borden, M. and Childs, B. (1961). Idiopathic hyperglycinemia: a new disorder of amino acid metabolism. II The concentrations of other amino acids in the plasma and their modification by the administration of leucine. Pediatrics, 27, 539.

- and Childs, B. (1962). Hyperglycinemia: The turnover rate of glycine, pool size, and the formation of serine. (Trans. Soc. pediat. Res., 32nd annual meeting.) Amer. J. Dis. Child., 104, 509.

, Chisolm, J. J., Jr. and Edwards, R. O., Jr. (1963). Idiopathic hyperglycinuria. III. Report of a second case. J. Pediat., 62. 540.

Puranen, J., Puranen, A. L. and Hallman, N. (1958). Determination of plasma glutamine by high-voltage paper electrophoresis. Ann. Paediat. Fenn., 4, 203.

Schafer, I. A., Scriver, C. R. and Efron, M. L. (1962). Familial hyperprolinemia, cerebral dysfunction and renal anomalies occurring in a family with hereditary nephropathy and deafness. New Engl. J. Med., 267, 51.

Stein, W. H. and Moore, S. (1954). The free amino acids of human blood plasma. J. biol. Chem., $211,915$.

Towers, G. H. N., Thompson, J. F. and Steward, F. C. (1954). The detection of the keto acids of plants. A procedure based on their conversion to amino acids. J. Amer. chem. Soc., 76, 2392.

Woody, N. C., Woody, H. B. and Tilden, T. D. (1963). Maple sugar urine disease in a negro infant. Amer. J. Dis. Child., 105, 381. 